\title{
ВОЗДЕЙСТВИЕ РЕКРЕАЦИОННОЙ НАГРУЗКИ НА КОМПОНЕНТЫ ЛЕСНОГО ФИТОЦЕНОЗА
}

\author{
А.А.Селиванов ${ }^{1}$, Д.Зоёо ${ }^{2}$, Д.Цээндсүрэн ${ }^{3}$ \\ ${ }^{I}$ Санкт-Петербургская государственная лесотехническая академия РФ \\ ${ }^{2}$ Ботанический институт АН Монголии, zоуо@botany.mas.ac.mn \\ 3Институт Геоэкологии АН Монголии, tsendsuren@ecology.mas.ac.mn
}

\section{Введение}

В последние годы лесные массивы зеленой зоны г. Улан-Батор, стали местом массового отдыха. Растущая урбанизация, изменившиеся экономические условия, интенсификация труда, все более усиливающаяся стрессовая ситуация увеличивают потребность городского населения в загородном отдыхе, в естественной природной обстановке. В сферу рекреации попадают все новые лесные территории, рекреационные нагрузки возрастают, вызывая ухудшение качественного состояния леса, а в некоторых случаях и его полную необратимую деградацию. Снижаются средообразующие, санитарно-гигиенические, климаторегулирующие, водоохранные и почвозащитные функции лесов зеленой зоны, теряется их эстетическая ценность.

Для того чтобы оценивать уровень рекреационной нарушенности лесных биогеоценозов, обязательно необходимо учитывать состояние растительности нижних ярусов, которая не только сама по себе является важным компонентом биогеоценозов, но и служит тонким индикатором состояния биогеоценоза в целом.

В литературе имеются сведения о том, что именно нарушения лесных фитоценозов способствуют росту разнообразия. В работе В.Т.Ярмишко ([6]) отмечается, что при нарушениях лесных экосистем, возникающих в результате пожаров, наблюдается рост видового разнообразия живого напочвенного покрова. Другой тип антропогенного воздействия - атмосферное загрязнение, напротив, вызывает постепенное снижение видовой насыщенности лесных фитоценозов. По результатам исследований Ч.Доржсүрэн [2] и Д.Зоёо [3] установлено, что в подтаежных лиственничных и сосновых лесах после пожаров высокой интенсивности формируются кипрейные сообщества, т.е. происходит процесс трансформации лесных сообществ.

Таким образом, характер изменения лесных сообществ под влиянием антропогенных воздействий в горных лесах отличается от изменений в равнинных лесах. Характерная особенность горных лесов заключается в их чрезвычайной динамичности и уязвимости по сравнению с равнинными лесами. Горные леса более чувствительны к загрязнению природной среды, к различным формам влияния человека, особенно к чрезмерным рекреационным нагрузкам ([4]). В связи с этим изучение характера изменений видового 
разнообразия лесных сообществ даст возможность своевременного предотвращения начала необратимых процессов деградации насаждений, испытывающих высокие рекреационные перегрузки.

\section{Методика исследования}

Для оценки воздействия рекреационного лесопользования на состояние лесных сообществ нами были заложены постоянные пробные площади (в дальнейшим отмечаем ППП) в лесах зеленой зоны города Улан-Батор, где рекреационное лесопользование наиболее интенсивно. Разнотравно-осочковый подтаежный лиственничник один из самых распространенных типов леса в зеленой зоне города. Чтобы изучать динамику изменения биологического разнообразия разнотравно-осочкового подтаежного лиственничника под воздействием рекреационной нагрузки изучены растительности нижних ярусов лесных сообществ с разной степенью рекреационной нагрузки, в каждой которой заложены постоянные пробные площади (Хб - контрольная, Ш , Хт, Ш $_{2}$ ). При выборе участков для исследования предусматривали сопоставимость их по основным таксационным и типологическим показателям лесных сообществ, находящихся под влиянием различных уровней рекреационной нагрузки и в фоновых условиях ([5]). Описание и учет растительного покрова на постоянных пробных площадях осуществлено на 10-15 учетных площадках размером 2 х2 м. Степень сходства растительного покрова на пробных площадях и коренного леса, а также однородность состава и строения напочвенного покрова на постоянных пробных площадях оценивали с помощью коэффициента сходства между учетными площадками по видовому составу (по формуле Съеренсена) и по ценотической значимости слагающих их видов методом наименьших сумм ([1]).

\section{Результаты исследований и их обсуждение}

Пробные площади заложены в пади Шаргаморьт (Ш $\left.{ }_{1}, Ш_{2}\right)$, Хурэлтогоот (ППП Хт) и Хандгайтын богино (ППП Хб. ) зеленой зоны г. Улан-Батор. В пади Шаргаморьт первые дачные дома построены в 1960 году, а несколько позже был построен пионерский лагерь. В настоящее время на территории этой пади находятся наибольшее количество рекреационных объектов по сравнению с другими падями. С этого времени прилегающий лесной массив стал подвергаться серьезному рекреационному воздействию. Пробная площадь Ш заложена в квартале № 2423 на высоте 1482 м над уровнем моря, с координатами N4803'294» E1065'ㄴㄷㄱ (C3). Почва горная дерново-таежная сезонномерзлотная. Экспозиция склона северная, крутизной $16^{\circ}$. Тип леса злаково-разнотравный лиственничник, III класса бонитета. Состав древостоя 10Лц+Б, полнота 0.7. Разреженно стоящие крупные деревья лиственницы обеспечивают хорошую проходимость, рекреанты могут свободно 
перемещаться по всем направлениям. Встречаются сильно вытоптанные участки. Имеются единичные экземпляры подроста, из них 70\% неблагонадежные. На каждой учетной площадке насчитывается в среднем 2-3 штуки всходов, но не встречается подрост 3-5 летнего возраста. Подлесок с проективным покрытием $2.8 \%$ состоит из Spiraea media F.Schmidt, Rosa acicularis Lindl., Cotoneaster mongolica Pojark. Живой напочвенный покров имеет 40.5\% проективного покрытия. Основные представители: Festuca ovina L., Carex amgunensis F.Schmidt, Fragaria orientalis Losinsk., Bromus pumpellianus Scribn., Sanguisorba officinalis L., Aegopodium alpestre Ldb., Lathyrus humilis (Ser.) Spreng., Chrysanthemum zawadskii Herb.

Следующая пробная площадь - Ш заложена в участке пади Шаргаморьт с умеренной рекреационной нагрузкой имеет координаты N4803'185» E10654'845», высота 1551 м над уровнем моря, северный склон крутизной $14^{\circ}$, заложена на территории шестого выдела в 2423-ом квартале. Почва горная дерново-таежная сезонномерзлотная. Состав

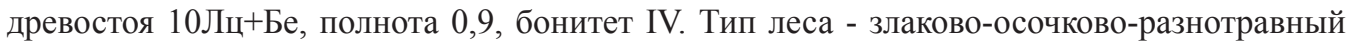
лиственничник. Подрост представлен лиственницей сибирской и сосной сибирской кедровой. Густота - 1.2 тыс.шт./а. Подлесок более густой, чем на ППП Ш покрытие составляет 6,3\% и представлен Spiraea media F.Schmidt, Juniperus sibirica, Rosa acicularis Lindl. Живой напочвенный покров главным образом представлен Festuca ovina L., Carex amgunensis F.Schmidt, Fragaria orientalis Losinsk., Bromus Pumpellianus Scribn., Chrysanthemum Zawadskii Herb., проективное покрытие - 50.5\%.

Пробная площадь Хт заложена на юго-востоке от города Улан-Батор, в пади Хурэлтогоот хребта Богдхан (квартал № 15). Рядом с лесным участком, где заложена пробная площадь, построен «Научный центр астрономии» и дом отдыха «Цагаан-Уул» академии наук Монголии, в связи с этим участок испытывает высокую рекреационную нагрузку. Насаждение находится на высоте 1636 м над уровнем моря, с координатами $\mathrm{N} 47^{\circ} 51^{\prime} 48.4 » \mathrm{E} 107^{\circ} 03^{\prime} 10.9 »$. Почва горная дерново-таежная сезонномерзлотная. Тип леса - злаково-осочково-разнотравный подтаежный лиственничник на северо-восточном склоне крутизной $8^{\circ}$. Древостой двухярусный, чистый по составу, состоит из лиственницы сибирской. Подрост очень редкий состоит из лиственницы сибирской - 0,219 тыс.шт./ га и 57\% экземпляров неблагонадежные и усохшие. Подлесок образуют Spiraea media F.Schmidt и Rosa acicularis Lindl с проективным покрытием 4\%. Живой напочвенный покров с проективным покрытием 43\%, представлен следующими видами: Festuca ovina L., Carex lanceolata Boott., Fragaria orientalis Losinsk., Vicia baicalensis (Turcz.) B.Fedtsch., Aegopodium alpestre Ldb. и Carex amgunensis F.Schmidt.

В 22 км на север от города Улан-Батор, на левой стороне долины реки Сэлбэ, в квартале № 2400 заложена ППП Хб , которую нами была выбрана в качестве контрольной. Лесной участок, в котором заложена ППП Хб, относительно слабо подвергается воздействию рекреации и лесная растительность на нем не нарушена, так как биоразнообразие имеет 
типичный вид для разнотравно-осочкового лиственничного типа леса. Пробная площадь Хб заложена на северо-западном склоне крутизной $14^{\circ}$, на высоте 1571 м над уровнем моря, с координатами N48 $05^{\prime} 42.3 »$ Е106 $54^{\prime} 27.6 »$. Тип леса - разнотравно-осочковом подтаежном лиственничнике. Почва горная дерново-таежная сезонномерзлотная. Древостой одноярусный с составом 9Лц 1 С+Б ед.К, класс бонитета III. Подрост средней густоты - 3.3 тыс.шт/га, состоит из сосны сибирской. Подлесок представлен Spiraea media F.Schmidt, Rosa acicularis Lindl с проективным покрытием 4\%. Живой напочвенный покров имеет проективное покрытие 64\%. Главными представителями являются Сагех amgunensis F.Schmidt и lanceolata Boott., Fragaria orientalis Losinsk., Iris ruthenica Ker.Gawl., Festuca ovina L., Lathyrus humilis (Ser.) Spreng., Bromus inermis Leyss., Viola biflora L., Galium boreale L. и Geranium pseudosibiricum I. Mayer.

Из состояния насаждений видно, что в лесах рекреационного лесопользования (на пробных площадях $Ш_{2}, Ш_{1}, \mathrm{XT}_{\text {) }}$ снижается количество подроста и изреживается подлесок. На фоне снижения количества подроста и изреживания подлеска идет рост количества видов травянистых растений (контроль-40 видов; ППП с умеренной нагрузкой - 42 видов) (Табл.1).

Таблица 1. Среднее число видов в лесах, подвергнутых воздействию рекреационного лесопользования с различной нагрузкой

\begin{tabular}{|c|c|c|c|c|}
\hline \multirow{3}{*}{\begin{tabular}{|} 
Показатели \\
Пробные площади
\end{tabular}} & \multirow{3}{*}{$\begin{array}{c}\begin{array}{c}\text { Ненарушенное } \\
\text { сообщество } \\
\text { (контроль) }\end{array} \\
\text { Хб } \\
\end{array}$} & \multicolumn{3}{|c|}{ Леса с рекреационной нагрузкой } \\
\hline & & умеренной & \multicolumn{2}{|c|}{ сильной } \\
\hline & & $\amalg_{2}$ & $\amalg_{1}$ & $\mathrm{X}_{\mathrm{T}}$ \\
\hline Количество видов насаждений & 45 & 47 & 43 & 39 \\
\hline $\begin{array}{l}\text { Количество видов травяно- } \\
\text { кустарничкого яруса }\end{array}$ & 40 & 42 & 39 & 37 \\
\hline
\end{tabular}

Таким образом, на начальных стадиях рекреационного лесопользования наблюдается рост видового разнообразия травяно-кустарничковых растений в подтаежном лиственничнике (Табл. 1). По мере дальнейшего увеличения нагрузки количество видов травяно-кустарничковых растений снижается (ППП с сильной рекреационной нагрузкой 39 и 37 видов), из-за исчезновения лесных видов.

Кроме того, наблюдается снижение проективного покрытия живого напочвенного покрова по мере увеличения роста рекреационной нагрузки (Табл.2). 
Таблица 2. Видовое разнообразие и проективное покрытие напочвенного покрова в подтаежных лиственничниках, под воздействием рекреационной нагрузки

(S- среднее значение проективного покрытия, \%; P-встречаемость, \%)

\begin{tabular}{|c|c|c|c|c|c|c|c|c|c|}
\hline \multirow{4}{*}{ № } & \multirow{4}{*}{$\begin{array}{l}\text { Виды растений травяно- } \\
\text { кустарничкового и мохового } \\
\text { ярусов } \\
\text { Пробные площади } \\
\text { Показатели }\end{array}$} & \multirow{3}{*}{\multicolumn{2}{|c|}{$\begin{array}{c}\text { Ненарушен. } \\
\text { сообщество } \\
\text { (контроль) }\end{array}$}} & \multicolumn{6}{|c|}{ Леса с рекреационной нагрузкой } \\
\hline & & & & \multicolumn{2}{|c|}{ умеренной } & \multicolumn{4}{|c|}{ сильной } \\
\hline & & & & \multicolumn{2}{|c|}{$\amalg_{2}$} & \multicolumn{2}{|c|}{$\amalg_{1}$} & \multicolumn{2}{|c|}{$\mathrm{X}_{\mathrm{T}}$} \\
\hline & & $\mathrm{P}$ & $\mathrm{S}$ & $\mathrm{P}$ & $\mathrm{S}$ & $\mathrm{P}$ & $\mathrm{S}$ & $\mathrm{P}$ & $\mathrm{S}$ \\
\hline 1 & 2 & 3 & 4 & 5 & 6 & 7 & 8 & 9 & 10 \\
\hline \multicolumn{2}{|c|}{ Кустарничниковый ярус } & 100 & 5.0 & 100 & 6.3 & 100 & 2.8 & 100 & 4.2 \\
\hline 1 & Spiraea media F.Schmidt & 100 & 2.6 & 100 & 3.1 & 87 & 1.4 & 100 & 2.1 \\
\hline 2 & Rosa acicularis Lindl. & 83 & 2.4 & 40 & 0.5 & 93 & 1.1 & 100 & 2.1 \\
\hline 3 & Juniperus sibirica Burgsd. & - & - & 10 & 2.5 & - & - & - & - \\
\hline 4 & Cotoneaster mongolica Pojark. & - & - & 50 & 0.2 & 33 & 0.3 & - & - \\
\hline \multicolumn{2}{|c|}{ Травяной ярус } & 100 & 64.2 & 100 & 50.1 & 100 & 40.5 & 100 & 42.7 \\
\hline 1 & Aegopodium alpestre Ldb. & 92 & 0.9 & 100 & 0.9 & 100 & 0.6 & 100 & 0.8 \\
\hline 2 & Carex lanceolata Boott. & 67 & 11.7 & - & - & - & - & 100 & 10.3 \\
\hline 3 & Carex amgunensis F.Schmidt & 100 & 15.9 & 100 & 9.0 & 100 & 7.1 & 90 & 0.4 \\
\hline 4 & Fragaria orientalis Losinsk. & 100 & 9.3 & 80 & 5.2 & 87 & 3.1 & 100 & 3.9 \\
\hline 5 & Galium boreale L. & 100 & 1.3 & 90 & 0.5 & 93 & 0.5 & 30 & 0.1 \\
\hline 6 & Geranium pseudosibiricum I. Mayer & 67 & 1.3 & 100 & 0.8 & 87 & 0.5 & 40 & 0.2 \\
\hline
\end{tabular}

Продолжение таблицьы 2.

\begin{tabular}{|c|c|c|c|c|c|c|c|c|c|}
\hline 1 & 2 & 3 & 4 & 5 & 6 & 7 & 8 & 9 & 10 \\
\hline 7 & Lathyrus humilis (Ser.) Spreng. & 100 & 2.3 & 80 & 0.6 & 87 & 0.5 & 40 & 0.2 \\
\hline 8 & Poa sibirica Roshev. & 100 & 0.5 & 90 & 0.8 & 67 & 0.4 & 100 & 0.7 \\
\hline 9 & Ranunculus japonicus Thunbg. & 50 & 0.3 & 40 & 0.3 & 60 & 0.3 & 80 & 0.4 \\
\hline 10 & Sanguisorba officinalis L. & 83 & 0.9 & 90 & 0.9 & 100 & 0.8 & 70 & 0.5 \\
\hline 11 & Festuca ovina $\mathrm{L}$. & 92 & 2.5 & 100 & 22.0 & 100 & 18.8 & 100 & 17.3 \\
\hline 12 & Vaccinium vitis-idaea L. & 8 & 0.0 & - & - & - & - & - & - \\
\hline 13 & Cerastium cerastoides Britt. & 58 & 0.5 & - & - & - & - & - & - \\
\hline 14 & Trollius asiaticus L. & 25 & 0.2 & 10 & 0.1 & 20 & 0.1 & - & - \\
\hline 15 & Moehringia lateriflora (L.) Fenzl & 58 & 0.3 & - & - & - & - & - & - \\
\hline 16 & Scorzonera radiata Fisch. & 8 & 0.0 & 20 & 0.1 & 13 & 0.1 & - & - \\
\hline 17 & Atraqene sibirica $\mathrm{L}$. & 50 & 0.4 & 30 & 0.2 & 13 & 0.1 & - & - \\
\hline 18 & Pyrola incarnata (DC.) Freyn & 8 & 0.0 & - & - & 27 & 0.2 & - & - \\
\hline 19 & Chrysanthemum Zawadskii Herb. & 67 & 0.5 & 100 & 1.0 & 67 & 0.5 & 70 & 0.7 \\
\hline 20 & Artemisia tanacetifolia $\mathrm{L}$. & 92 & 0.9 & 90 & 0.6 & 20 & 0.1 & 100 & 0.7 \\
\hline 21 & Vicia baicalensis (Turcz.) B.Fedtsch. & 50 & 1.1 & 30 & 0.2 & 60 & 0.3 & 100 & 1.1 \\
\hline 22 & Vicia cracca $\mathrm{L}$. & 100 & 1.0 & 60 & 0.4 & 87 & 0.4 & - & - \\
\hline 23 & Viola biflora $\mathrm{L}$. & 100 & 1.6 & 70 & 0.4 & 40 & 0.2 & - & - \\
\hline 24 & Iris ruthenica Ker.-Gawl. & 100 & 5.4 & 10 & 0.1 & - & - & 30 & 0.2 \\
\hline 25 & Calamagrostis obtusata Trin. & 25 & 0.2 & - & - & - & - & - & - \\
\hline 26 & Elymus sibiricus L. & 8 & 0.0 & - & - & - & - & - & - \\
\hline 27 & Thalictrum minus L. & 17 & 0.1 & - & - & - & - & 40 & 0.2 \\
\hline 28 & Aconitum barbatum Pers. & 67 & 0.6 & - & - & - & - & - & - \\
\hline 29 & Geranium pratense L. & 42 & 0.5 & - & - & - & - & 20 & 0.1 \\
\hline 30 & Anemone crinita Juz. & 25 & 0.2 & - & - & - & - & - & - \\
\hline 31 & Campanula glomerata $\mathrm{L}$. & 50 & 0.5 & 10 & 0.1 & 27 & 0.1 & 20 & 0.1 \\
\hline
\end{tabular}




\begin{tabular}{|c|c|c|c|c|c|c|c|c|c|}
\hline 32 & Bromus inermis Leyss. & 83 & 2.0 & - & - & - & - & & \\
\hline 33 & Artemisia sericea Web. ex Stechm. & 8 & 0.1 & 60 & 0.3 & 47 & 0.2 & 40 & 0.6 \\
\hline 34 & $\begin{array}{l}\text { Polemonium racemosum (Regel) } \\
\text { Kitam. }\end{array}$ & 25 & 0.2 & - & - & - & - & - & - \\
\hline 35 & Trisetum sibiricum Rupr. & 33 & 0.2 & - & - & - & - & 70 & 0.5 \\
\hline 36 & Rubus saxatilis L. & 25 & 0.5 & 10 & 0.1 & - & - & - & - \\
\hline 37 & Achillea asiatica Serg. & 8 & 0.1 & - & - & - & - & - & - \\
\hline 38 & Silene sibirica & 8 & 0.0 & - & - & - & - & - & - \\
\hline 39 & Bromus Pumpellianus Scribn. & - & - & 100 & 1.9 & 100 & 2.8 & 100 & 0.7 \\
\hline 40 & Geranium Vlassovianum Fisch. & - & - & 90 & 0.6 & 73 & 0.4 & 30 & 0.2 \\
\hline 41 & $\begin{array}{l}\text { Polygonum alopecuroides Tturcz. ex } \\
\text { Meissn. }\end{array}$ & - & - & 20 & 0.1 & 53 & 0.3 & 80 & 0.4 \\
\hline 42 & Potentilla nivea L. & - & - & 60 & 0.4 & 20 & 0.1 & - & - \\
\hline 43 & Viola sacchalinensis Biossieu & - & - & 90 & 0.5 & 33 & 0.2 & - & - \\
\hline 44 & Agrostis mongolica Roshev. & - & - & 80 & 0.5 & 53 & 0.4 & - & - \\
\hline 45 & Achillea millefolium $\mathrm{L}$. & - & - & 20 & 0.1 & 47 & 0.3 & 30 & 0.2 \\
\hline 46 & Aster alpinus $\mathrm{L}$. & - & - & 50 & 0.5 & 33 & 0.2 & & \\
\hline 47 & Taraxacum officinale Wigg. & - & - & 20 & 0.1 & 27 & 0.1 & 10 & 0.1 \\
\hline 48 & Phlomis tuberosa $\mathrm{L}$. & - & - & 30 & 0.2 & 13 & 0.1 & - & - \\
\hline 49 & Veronica incana $\mathrm{L}$. & - & - & 10 & 0.1 & - & - & - & - \\
\hline 50 & Dianthus superbus L. & - & - & 60 & 0.6 & 53 & 0.5 & - & - \\
\hline 51 & Chrysanthemum Zawadskii Herb. & - & - & - & - & - & - & - & - \\
\hline 52 & Valeriana officinalis L. & - & - & 40 & 0.3 & 13 & 0.1 & 80 & 0.5 \\
\hline 53 & Aquilegia sibirica Lam. & - & - & 10 & 0.1 & - & - & - & - \\
\hline 54 & Orchis salina Turcz. Ex Lindl. & - & - & 10 & 0.1 & - & - & - & - \\
\hline 55 & $\begin{array}{l}\text { Vicia venosa (Willd.ex Link.) } \\
\text { Maxim }\end{array}$ & - & - & 30 & 0.2 & - & - & 10 & 0.1 \\
\hline 56 & Campanula Turczaninovii Fed. & - & - & - & - & 13 & 0.1 & 10 & 0.1 \\
\hline 57 & Myosotis sylvatica (Ehrh.) Hoffm. & - & - & - & - & 6.7 & 0.03 & & \\
\hline 58 & Trifolium lupinaster $\mathrm{L}$. & - & - & - & - & 33 & 0.2 & 40 & 0.2 \\
\hline 59 & Trientalis europaea $\mathrm{L}$. & - & - & - & - & - & - & 10 & 0.1 \\
\hline 60 & Aconitum Czekanovskyi Steinb. & - & - & - & - & - & - & 50 & 0.2 \\
\hline 61 & Saussurea elongata DC. & - & - & - & - & - & - & 30 & 0.2 \\
\hline 62 & Artemisia integrifolia $\mathrm{L}$. & - & - & - & - & - & - & 50 & 0.5 \\
\hline 63 & $\begin{array}{l}\text { Chamaenerion angustifolium (L.) } \\
\text { Scop. }\end{array}$ & - & - & - & - & - & - & 30 & 0.2 \\
\hline 64 & Geranium eriostemon Fisch. & - & - & - & - & - & - & 10 & 0.1 \\
\hline
\end{tabular}

Из таблицы видно, что с увеличением рекреационной нагрузки уменьшается проективное покрытие живого напочвенного покрова, и постепенно исчезают характерные лесные виды травяно-кустарничкового яруса (Carex lanceolata Boott., Iris ruthenica Ker.Gawl., Trisetum sibiricum Rupr.,) или уменьшается проективное покрытие их (Artemisia tanacetifolia L., Fragaria orientalis Losinsk., Artemisia sericea Web.ex Stechm., Geranium pseudosibiricum I.Mayer). В состав яруса внедряются степные, луговые и сорные виды (Geranium Vlassovianum Fisch., Achillea millefolium L., Taraxacum officinale Wigg., Trifolium lupinaster L, Vicia venosa Willd.ex Link. и т.д.).

На участке с рекреационной нагрузкой коэффициент сходства по ценотической -36 - 
значимости по сравнению с контрольным лесным участком составляет 43.3\%, по видовому составу 58.53\%, которые показывают, как изменяется видовой состав живого напочвенного покрова.

Результаты определения абсолютно сухого веса надземной фитомассы по биосистематическим группам отражены на графике (Рис.1). Запас надземной фитомассы трав на контрольном участке составил 6.4 ц/га, на участке с умеренной рекреационной нагрузкой был 4.4 ц/га, а на участке с высокой рекреационной нагрузкой -2.7 ц/га.

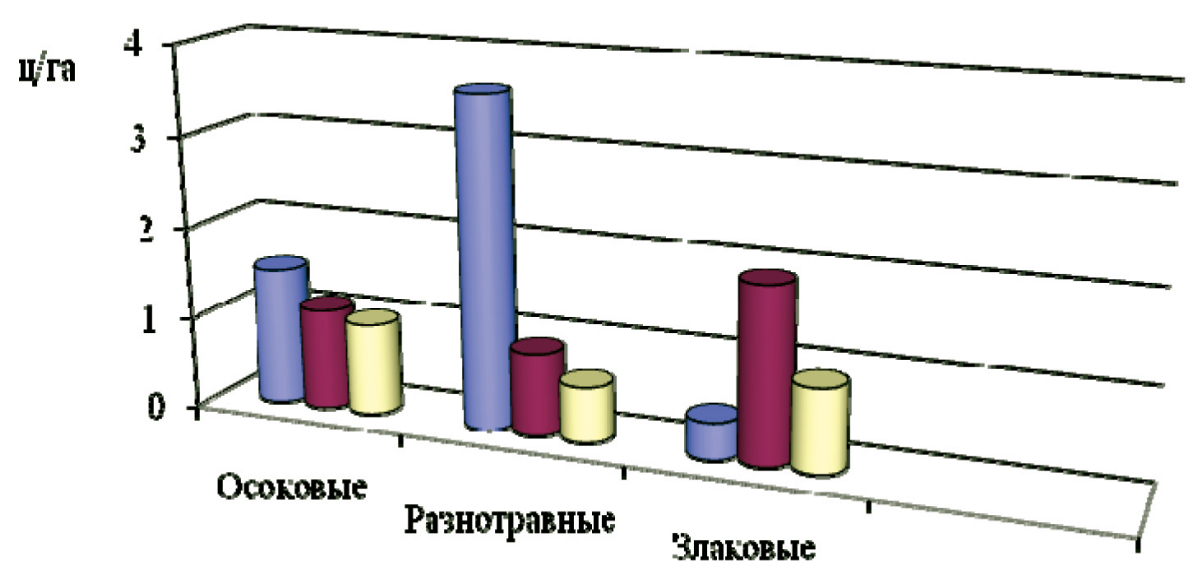

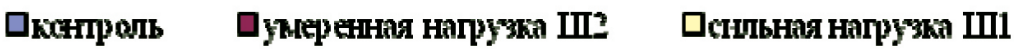

Рисунок 1. Надземная фитомасса живого напочвенного покрова по биосистематическим группам в прочентах.

Результаты определения фитомассы по биосистематическим группам живого напочвенного покрова показывают, что в подтаежном разнотравно-осочковом лиственничнике с возрастанием рекреационной нагрузки снижается фитомасса напочвенного покрова. С появлением рекреационной нагрузки фитомасса разнотравья уменьшается, а фитомасса злаковых резко увеличивается. Это объясняется тем, что с появлением рекреационной нагрузки расширяется видовой состав живого напочвенного покрова с внедрением лесостепных и лесолуговых видов. В дальнейшем с увеличением рекреационной нагрузки исчезают лесные таежные виды из состава напочвенного покрова, а также уменьшается и доля разнотравья.

В ценотическом сложении травяно-кустарничкового яруса ненарушенного сообщества доминируют лесные виды Carex amgunensis F.Schmidt (15,9\%), Carex lanceolata Boott. (11.7\%), Fragaria orientalis Losinsk. (9.3\%), Iris ruthenica Ker.-Gawl. (5.4\%), в составе эколого-ценотических групп преобладают лесолуговые (21 видов, 56.7\%) и лесные виды (10 видов, 27.03\%) (Рис.2). 


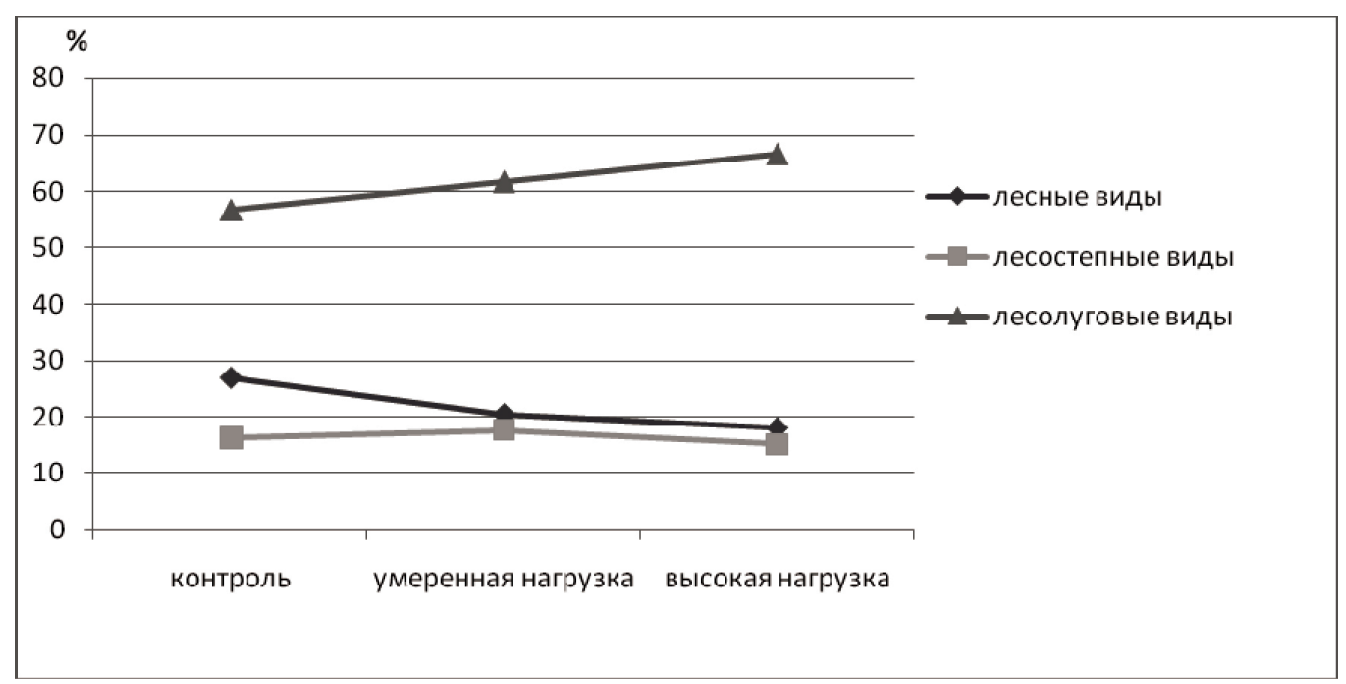

Рисунок 2. Динамика видового состава травяно-кустарничникового яруса на пробных площадях по эколого-цеенотическим группам

В лесах с умеренной рекреационной нагрузкой проективное покрытие травянокустарничкового яруса составляет 50.1\%, преобладают Festuca ovina L. (22\%), Carex amgunensis F.Schmidt (9.0\%) и Fragaria orientalis Losinsk. (5.2\%). Уменьшилось проективное покрытие Iris ruthenica Ker.-Gawl. (0.1\%), Geranium pseudosibiricum I. Mayer. (0.8\%). В живом напочвенном покрове господствуют лесолуговые (21 видов, 61.7\%) и лесные виды (7 видов, 20.59\%)

Под влиянием высокой рекреационной нагрузки в подтаежном разнотравноосочковом лиственничнике исчезли некоторые лесные виды такие, как Iris ruthenica Ker.Gawl., Trisetum sibiricum Rupr., Carex lanceolata Boott.. В эколого-ценотическом спектре преобладают лесолуговые виды (22 видов, 66.67\%).

Таким образом, под влиянием высокой рекреационной нагрузки в подтаежном разнотравно-осочковом лиственничнике проективное покрытие травяно-кустарничкого яруса постепенно уменьшается. На начальных стадиях рекреационного лесопользования наблюдается рост видового разнообразия травяно-кустарничковых растений, по мере дальнейшего увеличения нагрузки видовой состав травяно-кустарничковых растений снижается, так как исчезают характерные лесные виды, как Iris ruthenica Ker.-Gawl., Trisetum sibiricum Rupr., Carex lanceolata Boott.. В эколого-ценотическом спектре преобладают лесолуговые виды.

Из анализа данных видно, что на участках, находящихся вблизи с дачами увеличивается проективное покрытие овсяницы овечьей (Festuca ovina L.). Исходя из этого можно сделать вывод, что на этих участках идет ксерофитизация и интенсивная деградация растительных сообществ. 


\section{Выводы:}

Из всего выше сказанного можем сделать вывод о том, что в горных лесах под воздействием рекреационного лесопользования идет изменение структуры лесных сообществ. Разнотравно-осочковый подтаежный лиственничник переходит в злаковоосочково-разнотравный, с одновременной ксерофитизацией и интенсивной деградацией растительных сообществ.

Под влиянием рекреационной нагрузки в разнотравно-осочковом подтаежном лиственничнике проективное покрытие травяно-кустарничкого яруса постепенно уменьшается. На начальных стадиях рекреационного лесопользования наблюдается рост видового разнообразия травяно-кустарничковых растений, по мере дальнейшего увеличения нагрузки видовой состав травяно-кустарничковых растений снижается, так как исчезают характерные лесные виды, как Iris ruthenica Ker.-Gawl., Trisetum sibiricum Rupr., Carex lanceolata Boott. C возрастанием рекреационной нагрузки снижается фитомасса напочвенного покрова.

\section{Ном зүй}

1. Василевич В. И. Статические методы в геоботанике. - Л.: Наука, 1969. -232 с.

2. Доржсурэн Ч. Структура и антропогенная динамика растительных сообществ лиственничных лесов Монголии: Автореф. дисс. ... док. биол. наук по спец. / Институт леса им. В.Н.Сукачева СО РАН. - Красноярск, 2006. - 40 с.

3. Зоёо Д. Изменение травяно-кустарничковых ярусов в лиственничных и сосновых лесах под воздействием рубок и пожаров (на примере Хантайского и Сэлэнгинского лесорастительных округов): автореферат дисс. ... канд.биол.наук / Институт Ботаники АН Монголии. - Улан-Батор, 2000. -26 с.

4. Поляков А.Ф. Особенности рекреационного лесопользования в горных курортных районах Крыма // Лесоведение. -1993. - №4. - С.50-57.

5. Цэндсурэн Д. Состояние лиственничных насаждений (Larix sibirica Ledeb.) зеленой зоны г. Улан-Батор и перспективы их рекреационного использования: Автореферат дисс. ... канд. с.-х.наук. - Санкт-Петербург: СПбГЛТА, 2009. - 20 с.

6. Ярмишко В.Т. Характер изменений видового разнообразия нижних ярусов леса под влиянием антропогенных факторов // Известия Санкт-Петербургской лесотехнической академии: Вып.169. -СПб.: СПбГЛТА, - 2003. - с.205-216. 


\title{
РЕКРЕАЦИЙН АЧААЛАЛ ОЙН ФИТОЦЕНОЗЫН БУРЭЛДЭХУУНД НӨЛӨӨЛӨХ НЬ
}

\author{
А.А.Селиванов ${ }^{1}$, Д.Зоёоㄹ, Д.Цэндсүрэн ${ }^{3}$ \\ ОХУ-ын Санкт-Петербургийн ойн техникийн улсын академи \\ ${ }^{2}$ ШУА-ийн Ботаникийн хүрээлэн, zоyo@botany.mas.ac.mn \\ ${ }^{3}$ ШУА-ийн Геоэкологийн хүрээлэн, tsendsuren@ecology.mas.ac.mn
}

Сүүлийн жилүүдэд Улаанбаатар хотын хүн ам огцом ихээр нэмэгдэж байгаа нь хотын ногоон бүсэд салхинд гарч амрагчдын тоо ихсэх, хүний хөлийн талхлалд өртөх ойн талбайн хэмжээ өргөсөх үндсэн шалтгаан болж байна. Ойг амралт зугаалгын болон дагалт баялаг түҮх (рекреаци) зориулалтаар ашиглах явцад ойн фитоценозод ихээхэн өөрчлөлт ордог. Улмаар ойн агаарыг цэвэршүүлэх, хүчилтөрөгчийг ялгаруулах, цаг уур, усны горимыг зохицуулах үүрэг нь буурдаг. Ойн доод ташингын ургамлууд нь биогеоценозын чухал бүрэлдэхүүн болохын зэрэгцээгээр ойн фитоценозын өөрчлөлтийн гол илтгэгч нь байдаг. Улаанбаатар хотын ногоон бүсийн рекреацийн ачааллаараа ялгаатай ойнуудад өвслөг ургамлан бүрхэвчид төлөв байдлын үнэлгээ хийн судлахад алаг өвс-улалжит тайгархаг шинэсэн ойд өвслөг ургамлын бүрхэцийн хувь аажмаар буурч байна. Мөн рекреаци ашиглалтын эхний шатанд зүйлийн бүрэлдэхүүний тоо өсч, цаашид рекреацийн ачаалал ихсэх тусам зүйлийн бүрэлдэхүүн цөөрч, Iris ruthenica Ker.-Gawl., Trisetum sibiricum Rupr., Carex lanceolata Boott. гэх мэт ойн үндсэн зүйлүүд устан, хээрийн болон хөл газрын ургамлын зүйлүүд түрэн орж ирэх байдлаар өөрчлөлт орж байна. 